\title{
Supranational regulatory agencies between independence and control: the EMEA and the authorization of pharmaceuticals in the European Single Market
}

\section{Thomas Gehring and Sebastian Krapohl}

\begin{abstract}
The European Medicines Agency (EMEA) represents a new type of supranational regulation. Formally, it merely advises the Commission and a member state committee on the authorization of pharmaceuticals. In practice, however, it dominates decision-making and operates much like an independent agency. Based upon a brief discussion of the merits of independent regulation and the necessity to control regulatory activities, the article explores the institutional arrangement in which the EMEA is embedded and seeks to explain how tight oversight is compatible with quasi-independent action. It argues that the multi-tiered oversight mechanism restricts the non-scientific actors involved in the authorization of pharmaceuticals more than the agency - as long as the agency adheres to its mandate of producing scientifically convincing decisions.
\end{abstract}

KEY WORDS Delegation; EMEA; pharmaceuticals; regulatory agencies; Single Market regulation

\section{INTRODUCTION}

The relevance and nature of delegation for supranational governance within the European Union (EU) is increasingly explored by scholars of European integration. Whereas decision-making powers are predominantly delegated to the well-known supranational institutions, especially the Commission and the Court (Alter 1998; Pollack 2003), some regulatory tasks are assigned to separately established agencies. Generally, such delegation is subject to the tension between independent decision-making and close oversight. On the one hand, modern regulation theory demonstrates that regulatory decisions will improve, if intervention of actors with particularistic interests is precluded and agencies act as fiduciaries of the long-term interests of their principals with a considerable margin of discretion at their disposal (Majone 2001a, 2001b; Cukierman 1994). Hence, the degree of formal independence from government and parliamentary majorities ranks high in the appraisal of regulatory agencies (Gilardi 2002; Thatcher 2002). On the other hand, mainstream 
principal-agent theory emphasizes that regulatory agencies must be forced to follow their principals' interests (Kiewiet and McCubbins 1991; Pollack 2003), because as newly created actors they might otherwise pursue their own agendas.

This article examines how formal or informal independence is accommodated with oversight of decision-making activities within the European authorization system for pharmaceuticals. The European Medicines Agency (formerly the European Agency for the Evaluation of Medicinal Products, EMEA), which constitutes the cornerstone of the system, is among the most important supranational regulatory agencies founded in the EU during the last decade (Kelemen 2002; Krapohl 2004). It enjoys remarkably far-reaching competencies (Majone 1997) and may be conceived of as a blueprint for future agencies announced in the Commission White Paper on European Governance (COM 2001 [428] final). Although the agency did not acquire formal independence, it dominates the decision-making process for the authorization of medicinal products in the Single Market and virtually determines the content of authorization decisions, because it is well protected from interventions in its day-to-day decision-making by the member states and other political actors.

The implications of the institutional arrangement for the authorization of pharmaceuticals are increasingly heavily disputed among observers. Most contributions focus on the origins of the authorization system and correctly point out that it has been promoted by industry within the Single Market project, rather than by stakeholders with public health interests (Lewis and Abraham 2001: 62-5; Permanand and Mossialos 2005: 697-700). However, this does not elucidate how the tension between the demand for a science-based operation of the EMEA and the demand for its oversight is solved within the existing arrangement. Scholars focusing on the formal position of the member states and their domestic authorization administrations conclude that the member states refrained from giving up their control of the decision process (Kelemen 2002). Others argue that the quasi-independence of the agency supports the quality of regulatory decision-making (e.g. Majone and Everson 2001; Vogel 1998), and yet others, taking agency independence for granted, criticize the arrangement because of its lack of effective control which might foster a neocorporatist bias in favour of industry interests (e.g. Abraham and Lewis 2000: 147-71). Despite this critique, an extensive opinion survey conducted in 2001 on behalf of the Commission showed that most stakeholders support the centralized authorization procedure and appreciate the work of the EMEA. Over 90 per cent of the applying companies and all regulatory authorities of the then fifteen member states expressed their satisfaction with the procedure, while the two principal consumer groups - physicians and patients - were only slightly less positive (Cameron McKenna and Anderson Consulting 2001: 72-6). Moreover, the European system for the authorization of pharmaceuticals has been reinforced recently (by Regulation [EC] 726/2004, OJ No. L 136 of 30.4.2004; see Feick 2005). 
The article starts with a brief discussion of the benefits of regulation by independent agencies and explores oversight mechanisms which do not undermine the ability of the agency to produce reasonable regulatory decisions (section 2). Against this backdrop, it examines the operation of the European authorization system for pharmaceuticals with a particular view to the origins of the de facto independence of the EMEA and the mechanisms established for its control. It demonstrates that the multi-tiered oversight mechanism commits the EMEA, and all other actors involved-including the member states-to a rule-based decision-making process, which strictly limits the margin for opportunistic manoeuvre of all relevant actors (section 3). The article concludes that the complex oversight mechanism restricts the nonscientific actors involved in the authorization of pharmaceuticals more than the agency - as long as the agency adheres to its mandate of producing scientifically convincing decisions.

\section{REGULATION BY INDEPENDENT AGENCIES}

Recent theoretical work has pointed out that delegation follows two different logics, rather than a single one (Majone 2001a; Franchino 2002). On the one hand, a principal may desire to reduce transaction costs and mobilize executive branch expertise, so that the agent should, generally, decide as the principal would have done. On the other hand, a principal may delegate decisionmaking competencies to enhance the credibility of policy commitments, so that an agent is expected to decide differently from what the principal would have done. Whereas the former approach emphasizes control and oversight of the agent, the latter focuses upon its independence. In this section, we explore how the two approaches can be fruitfully combined.

\subsection{The case for independence of regulatory agencies}

Among the most important reasons for the delegation of regulatory functions to an independent agency ranks the problem of time-inconsistent preferences of one or more principals. As long as an actor is aware of his interests, and his preferences are consistent, he can usually act accordingly. Agents established for his assistance may be closely controlled because the agents are supposed to do exactly what the principal would have done himself. However, in many cases long-term interests militate against situation-specific short-term preferences (Keech 1995: $38-40$ ), so that action in the particular situation jeopardizes the pursuit of long-term interests. A state or government faced with a case of hostage-taking might tend to negotiate in order to save the lives of hostages, but the reputation of negotiating will provide a strong incentive to incur future crimes.

Modern regulatory theory argues that independent agencies are better suited for regulatory matters than tightly controlled state bureaucracies (e.g. Majone and Everson 2001), because they remedy the problem of inconsistent preferences (Cukierman 1994). To resist the temptation to act according to 
short-term preferences, an actor must sacrifice his discretion in the concrete situation and bind himself by an appropriate institutional restraint to a suitable 'mast' like Ulysses did in light of the Sirens. If he assigns implementing decisions to an agent unsusceptible to the temptations of specific situations, he will create a 'credible commitment' (Shepsle 1991), which binds himself as well as his successors. It is important that such an agent is able to act differently from what the principal would have done in his place - not as his slave, but as his 'fiduciary' (Majone 2001b).

Authorization of pharmaceuticals raises the problem of inconsistent preferences over time. Clinical testing of pharmaceuticals is extremely expensive and producers might depend economically on the authorization of a particular product. Patients might eagerly await authorization of a pharmaceutical which promises to cure a dangerous disease. Hence, decision-makers may be under considerable pressure from interest groups and single applicants to decide according to the particularities of the specific situation. However, pharmaceuticals can be extremely harmful. Not only are biologically or chemically highly active substances deliberately incorporated, consumers will also usually be unable to judge the quality of medicinal products themselves, so that information is typically asymmetrically distributed between producers and consumers (Feick 2000). The regulation of these products according to reliable and comparatively strict standards may be assumed to be in the long-term interest of society, because both consumers and producers benefit from a well-operating market.

Within the European Single Market, authorization of pharmaceuticals raises the additional problem of market integration. Generally, member states may be assumed to have an interest in market integration, allowing an accelerated recovery of the enormous development costs of modern pharmaceuticals for the benefit of industry (Lewis and Abraham 2001), but they might also be interested in selectively protecting non-competitive domestic industries. Moreover, public health matters remain located at the national level, so that the member states assume responsibility for the safety of pharmaceuticals marketed under their jurisdiction, whereas the task of opening originally protected markets for the free exchange of pharmaceuticals is a typical matter for supranational regulation (Permanand and Mossialos 2005: 688-90). If every member state seeks to rely as far as possible on its own domestic authorization system, none can benefit from market integration. Indeed, the traditional approach to an integrated market for pharmaceuticals prior to the introduction of the new European authorization scheme in 1993 proved to be a complete failure, because the member states regularly refused to recognize authorizations issued by other member states (Collatz 1996: 48; Gardner 1996: 52-5).

\subsection{How to control an agency without jeopardizing its independence}

Entrusting an independent agency with far-reaching competencies creates the danger of 'shirking', and requires arrangements to make the agency accountable 
for its decisions. It is not self-evident that a fully independent agency produces 'good' decisions, because bureaucracies may well develop and pursue their own interests, rather than those of their principals (Kiewiet and McCubbins 1991). They may also systematically prefer the perspectives of some stakeholders to those of others. In the present case, the well-organized producers of pharmaceuticals might manage to generate more effective pressure on a regulator than the heterogeneous group of consumers of these products (Lewis and Abraham 2001: 62-73; Abraham and Lewis 2002: 78-82). The danger of shirking will decrease, if an effective oversight system is installed to detect and possibly sanction problematic regulatory decisions. According to standard principalagent theory, possible sanctioning instruments include the redefinition, in extreme cases total withdrawal, of decision-making competencies, prescription of administrative procedures (McCubbins et al. 1987), as well as the restriction of budgetary resources (Huber 2000). Successful oversight does not necessarily require explicit action because an agent may anticipate sanctions and adapt to the principal's expectations (Pollack 2003: 202).

Unfortunately, particularistic interests might come back into day-to-day policy-making through direct sanctioning. The agent will not act within an arm's-length distance from the political sphere anymore, if its decisions are directly overseen by its principal. Direct intervention might effectively stop a regulatory system developing in a totally wrong direction, but it does not constitute an appropriate instrument for the fine-tuning of regulation in the day-today business (Gehring 2004: 690-2). Generally, more powerful sanctioning capacities of the principal are prone to weaken credible commitment to longterm policy objectives and reduce delegation gains (Tallberg 2002). Hence, the central issue is to allow the agency the discretion necessary for the proper discharge of its regulatory tasks, and to ensure at the same time that it does not overstep its competencies (Majone 2001a: 119).

The trade-off between the desirability of independent regulatory decisionmaking and the necessity of its tight control by the principal can be avoided if oversight functions are assigned to another agent. The task of controlling intended to minimize the dangers of 'shirking' and 'capture' of a regulatory agency does not have to be carried out by the principal (Kiewiet and McCubbins 1991: 33-4). Within the EU, control functions are frequently assigned to the European Commission and, indirectly, to the European Court of Justice. In this way, the original commitment of the principal to his long-term interest is not undermined, because he does not himself intervene in the day-to-day decision process. However, delegation of control functions raises the second-order control problem of who guards the guardians (Shapiro 1988). If we can expect agents to deviate from the principal's long-term interests unless an appropriate oversight system is in place, this will apply to agents fulfilling the control function as well.

The trade-off can also be sidestepped, if the discretion of an agency is constrained by substantive rules upon which decisions have to be based. Substantive rules provide guidance before a regulatory decision is made 
(Huber et al. 2001). They constitute the most definitive set of instructions that can be given to an agency with respect to the actions it must take during policy implementation. If carefully elaborated, they reflect, and elucidate, the longterm interests of the principal and inform the agency of the desired general direction of regulatory decision-making. They also provide a yardstick against which regulatory decisions adopted by the agency can be appraised ex post by any competent actor; for example, by a court. For the agency, they create an (implicit) requirement to 'give reasons' (Shapiro 1992) for its decisions, and provide incentives for the elaboration of appropriate internal procedures binding the agency to its commitments. In addition, the making of substantive rules creates constraints for the principals. If he does not know his interests in all future cases, because the mass of regulatory decisions is still unknown, he will favour criteria which promise reasonable decisions, even if not fitting his (yet unknown) parochial interests (Gehring 2004).

From the preceding discussion against the backdrop of the two competing strands of principal-agent theory, we can derive two conditions for efficient regulation against which the existing system for the authorization of pharmaceuticals in the Single Market can be appraised. First, regulation will be most efficient if the principals of the agency, namely the member states as well as the Commission and the European Parliament acting as the joint EU legislator, accept a credible commitment which effectively precludes their intervention in the dayto-day decision-making of the agency in order to avoid short-sighted decisions. Second, the agency must be effectively prevented from sidestepping the task assigned to it by its principals without reintroducing situation-specific considerations in the decision process through the back door.

\section{THE EMEA AND THE CENTRALIZED AUTHORIZATION OF PHARMACEUTICALS}

The European authorization system for pharmaceuticals was established in 1993 (Regulation (EEC) No. 2309/93, OJ No. L 214 of 24/8/1993) after mutual recognition had failed to produce a single market for medicinal products. It was revised in 2004 (Regulation (EC) No. 726/2004, OJ No. L 136 of 30/ $4 / 2004)$, whereby its central features were retained and strengthened. It was intended to establish a single European market for innovative, i.e. costly, pharmaceuticals, not to advance European health policy, and the member states retained full control of healthcare competencies, including budgets and drug prices. Thus, regulation has to ensure that authorized pharmaceuticals are reliable, rather than to enhance public health in Europe.

The centralized authorization procedure forms the centrepiece of the new system and is thus best suited for an assessment of its operation. It applies to all biotechnologically produced pharmaceuticals as well as products related to certain diseases (e.g. diabetes, cancer, Alzheimer's and AIDS), whereas other innovative products can be voluntarily authorized under the procedure. Less innovative products and generics, i.e. clones of already existing and authorized 
medicines, are authorized under the decentralized procedure based upon mutual recognition of member state authorizations. But arbitration following the same rules as the centralized authorization procedure will be started if mutual recognition fails. Decision-making by the EMEA is not only affected by the multistep authorization procedure (3.1), but also by the existence of substantive decision criteria and the highly developed system of European law (3.2), as well as by remarkable guidelines adopted by the EMEA to ensure consistency of its decisions that implicitly limit its room for opportunistic manoeuvre (3.3).

\subsection{The first layer: checks and balances of the authorization procedure}

The centralized authorization procedure establishes a system of differentiated decision-making which allocates particular functions to the different stages and actors involved. A producer submits its application to the EMEA, a London-based entity separate from the regular European institutions with its own budget, employees and director. An expert committee operating as part of the agency and supported by its administration elaborates a scientific opinion. Subsequently, the Commission transforms the opinion into a decision proposal. The formal decision is eventually taken by the Standing Committee for Human Medicinal Products, i.e. a Comitology committee in which the member states are represented. In case of conflict, decisions are referred to the Council. Hence, at least three actors, i.e. the EMEA, the Commission and the Standing Committee, are necessarily involved in every single authorization decision. The procedure is illustrated in Figure 1.

At first glance, the authorization procedure seems to be dominated by the member states and the Commission. No authorization decision can be adopted without the agreement of the Commission and the Standing Committee. Originally, the Committee operated according to the regulatory procedure, which provides that a proposal is referred to the Council, unless it is endorsed by a qualified majority of member states' votes. Later on, the management procedure was introduced according to which a Commission proposal can be blocked by a qualified majority of votes. Moreover, an authorization formally constitutes a Commission decision, so that the Commission, and not the EMEA, is legally accountable for it. In contrast, the agency appears to enjoy a

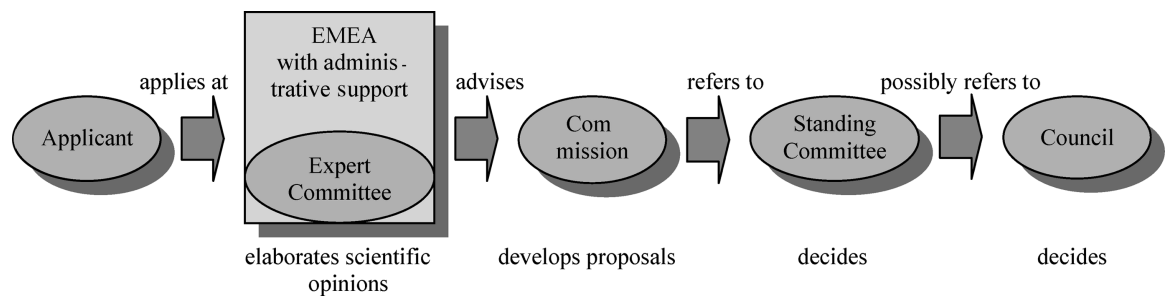

Figure 1 Centralized authorization procedure for pharmaceuticals 
comparatively weak formal status within the procedure. Since it is merely assigned the task of evaluating applications for the authorization of pharmaceuticals and of recommending decisions, it might appear to be a somewhat oversized scientific advisory committee fulfilling the function of a conditional agenda-setter in collaboration with the Commission (Tsebelis 1994). The strong formal control component is apparently designed to prevent the agency from ignoring the principal's interests. The member states lost their individual veto powers when the original system based upon mutual recognition of national authorizations was abolished. In addition, the European Court of Justice had, with its Meroni doctrine, closed the door for the extensive delegation of formal decision-making competencies to entities not empowered by the European treaties (Vos 1999: 200).

On closer inspection, the balance between the importance of scientific advisory functions and political control functions is almost completely reversed. The EMEA dominates the authorization procedure, while political control is almost negligible in practice. The strength of the agency originates from several sources which altogether reinforce its position as an agenda-setter for the ensuing decision stages and make it very difficult for the other actors involved to ignore its scientific opinions.

In contrast to regular scientific committees within the EU, involvement of the EMEA cannot be sidestepped. Producers apply for a marketing authorization directly at the EMEA and not at the Commission. Accordingly, the agency is not only always involved in the authorization process. It also operates at the first stage of the decision-making process and its scientific opinions inevitably set the agenda for subsequent decision stages. This is in sharp contrast to the traditional committee system, where the Commission enjoys the true agenda-setting power, because it is almost free to consult the expertise of scientific committees at will (Krapohl 2003).

Scientific opinions on applications are elaborated by an institutionalized network of experts from member state regulatory agencies within the Committee for Human Medicinal Products (CHMP; formerly the Committee for Proprietary Medicinal Products, CPMP). The members of this committee act in a personal capacity and are recruited preferably from the regulatory agencies of the member states which usually themselves act at arm's length from direct political intervention in their day-to-day business. This institutional arrangement implies that a draft opinion is scrutinized from the perspectives of a variety of different national regulatory cultures before being adopted or amended, so that decisions agreed upon within the committee are acceptable from the perspectives of at least a majority of domestic regulatory agencies. Decisions adopted within the EMEA will usually be difficult for the member states to challenge for scientific reasons, because their own expert administrations are closely involved in their elaboration and will not complain about a particular decision, unless it is considered as grossly unconvincing by an outvoted representative. The decision process is supported by the fact that committee members, especially the two rapporteurs preparing a draft scientific opinion, can draw upon the apparatuses of 
their national regulatory agencies to process the overwhelming amount of information included in an average application of some 250,000 pages (interviews at EMEA headquarters and at the German pharmaceutical authority [Bundesamt für Arzneimittel und Medizinprodukte]). Altogether, the appraisal of applications relies on a network of member state regulatory agencies (Dehousse 1997; Eberlein and Grande 2005; Majone 1997) which is similar to that of the European System of Central Banks.

Ironically, an EMEA expert committee composed of independent scientists would probably weaken, rather than strengthen, the position of the EMEA within the procedure. Originally, the European Parliament had struggled for an expert committee composed of independent scientists (OJ C 183 of 15/7/ 1991: 178), and in the recent reform process, it proposed selection of committee members by the EMEA executive director from a list provided by the member states (COM [2002] 735 final of 10/12/2002). In contrast to the current system, committee members would be more independent from the expert administrations of the member states. However, one person cannot handle the documentation of the several hundred thousand pages of which an application is composed. Currently, the few non-regulators in the committee must rely on the resources of their private institutes - which may be funded, directly or indirectly, by the pharmaceutical industry. Thus, more independence from the member states might lead to less independence from industries' interests. Alternatively, the EMEA, now basically an administrative support unit for the expert committee, would have to expand its own scientific and technical capacities dramatically. This step would necessarily entail a radical centralization of the regulatory system and would probably lead to more ex-post control of the agency by the Commission and the member states represented in the Standing Committee. Thus, more independence of the EMEA experts might lead to a weaker EMEA within the decision-making procedure.

Formal restrictions diminish the role of the Commission and the Standing Committee. The procedure provides strong incentives for the Commission to stick to the scientific opinion prepared by the EMEA. Not only is it obliged to justify a possible deviation from the EMEA opinion according to the rules of the authorization procedure (Gardner 1996: 56). In the case of scientific doubt, it cannot itself amend, or ignore, the opinion but must refer the matter back to the EMEA, where it is examined again by the expert committee. Decisive action within the Standing Committee is also restricted. The centralized authorization procedure does not envisage that member states regularly meet and discuss authorization decisions within the Standing Committee. Except for special cases, decisions will be adopted in a written procedure and are automatically passed if no member state objects within thirty days (Vos 1999: 212-13).

In practice, both the Commission and the Standing Committee have remained largely inactive over the last ten years. Not a single Commission proposal submitted up to May 2001 deviated from the scientific opinion of the EMEA expert committee (COM 2001 [404] final: 8-9) and the authors do 
not know of any such deviation in the time thereafter. The Commission does not even make use of a separate scientific apparatus to scrutinize the EMEA opinions. Consequently, the EMEA committee throughout determined the content of decision proposals prepared by the Commission for the Standing Committee. Likewise, the Standing Committee rarely decides anything actively (ibid.). Out of 262 authorization decisions, 253 were adopted according to the written procedure, and merely nine within regular meetings. Four of these nine decisions received unanimous support, while only five were supported by a qualified majority. Not a single decision proposal was eventually rejected by the committee and none was referred to the Council. Consequently, every final decision under the centralized authorization procedure reflects the relevant scientific opinion of the EMEA committee (figures include the decisions according to the arbitration procedure which operates exactly like the centralized procedure).

What is formally designed as an oversight mechanism of the police patrol type has in practice developed into a remote fire alarm system (McCubbins and Schwartz 1987). According to the formal procedure, both the Commission and the member states represented in the Standing Committee can examine every authorization decision prior to its adoption. In practice, neither of the oversight actors has established the necessary scientific apparatus for doing so. Employment of their formally strong decision-making power will thus depend on external alert. A 'fire alarm' may be raised in particular by an applying pharmaceutical company or by an outvoted member of the EMEA expert committee. However, the far-reaching inactivity of this oversight system does not imply that it is irrelevant for the authorization procedure (Pollack 2003: 202). It provides a permanent incentive for the EMEA expert committee to elaborate convincing opinions against which no relevant actor can seriously mobilize the oversight system. As a consequence, the EMEA virtually determines the content of authorization decisions, but it does so in the shadow of threatened intervention by the Commission and/or the Standing Committee. During the reform process, the member states refused to abolish this oversight stage. Whereas the Commission advocated cutting back the last stage of the authorization procedure (COM [2001] 404 final), because the formally powerful Standing Committee did not seem to fulfil any important function in practice, the member states merely accepted replacing the originally very restrictive regulatory procedure by a management procedure (Regulation [EC] 726/2004, arts. 10 and 87). Henceforth, the Standing Committee can block a decision by a qualified majority of member states' votes.

As a corollary to the inactivity of the political oversight system, the members of the EMEA expert committee appear to refrain from bargaining and resort to the elaboration of scientifically sound opinions. According to a survey conducted by the authors, scientific opinions are almost always adopted by a consensus of committee members. Of all together 242 opinions, issued from the setting into force of the centralized authorization procedure in 1995 until the end of 2002 and published by the EMEA on the Internet (www.emea.eu.int), 
only twenty-three were adopted by majority vote (Krapohl 2005: 119-30). If committee members were predominantly attempting to pursue the parochial interests of their member states and to resort to bargaining over individually preferred outcomes, we would expect that majorities might not hesitate to outvote remaining minorities. Hence, the prevailing consensus may be interpreted as indicating far-reaching substantive agreement with the decisions adopted by the committee. Its members appear to be well aware of the importance of scientifically reliable opinions for their collective reputation as an impartial scientific body.

The remarkable difference between the inferior formal status of the EMEA and its dominating actual position within the authorization process requires explanation. In spite of its inferior status as an advisory body, the expert committee dominates the authorization process, so that the EMEA operates in fact as if it were largely independent. Whereas the member states have formally retained the right to block any unwanted authorization decision, they do not use this right in practice. The almost complete absence of political intervention by the member states is difficult to explain by the authorization procedure alone, because this institutional arrangement lacks a device that could effectively hinder them from doing so. To assume that the member states simply do not want to interfere with the scientific authorization process begs the question of why they should behave systematically differently in other areas of European integration, where bargaining prevails, and even from their former behaviour concerning the authorization of pharmaceuticals, where the original procedure of mutual recognition did not work at all.

\subsection{The second layer: substantive decision criteria and judicial oversight}

Legally binding criteria for decision-making provide the foundation of another layer of the oversight mechanism. Acting as the European legislator, Commission, Council and Parliament have jointly enacted a large set of substantive criteria which are legally binding for all actors involved. Basic criteria are provided for in Council Regulation No. 2309/93 (replaced by Regulation [EC] 726/ 2004) establishing the EMEA and the centralized authorization procedure. Authorization decisions shall exclusively rely on the evaluation of the safety, efficacy and quality of a pharmaceutical - aside from narrowly defined exceptions to meet moral concerns (e.g. Irish concerns about pharmaceuticals for abortion). The broad criteria are specified by a detailed 'Community Code Relating to Medicinal Products for Human Use' now enshrined in Directive 2001/83/ EC (OJ L 311 of 28.11.2001: 67). Apart from fundamental definitions and some procedural rules, this code provides detailed standards for the medical tests to be passed by every pharmaceutical in order to obtain reliable data for its appraisal. Non-scientific factors like the economic well-being of the pharmaceutical industry or financial constraints of domestic healthcare systems shall be ignored. Occasional criticism of the EMEA for not founding its opinions on additional criteria such as general aspects of public health or for accepting 'me too' drugs with therapies for which pharmaceuticals already exist 
(Abraham and Lewis 2002; Permanand and Mossialos 2005) is thus implicitly directed at enlarging the discretion enjoyed by the agency.

The European courts join the 'authorization game' and will eventually decide on whether standards have been correctly applied or not. The relevance of European law and European courts for the authorization system for pharmaceuticals became evident in a judicial struggle about the authorization of anorectics, i.e. medicinal products against obesity. In 2000, the Commission withdrew market authorizations for an old group of these pharmaceuticals, which had been granted long before the establishment of the centralized authorization system by national authorization agencies (Decisions: C [2000] 452, C [2000] 453 and C [2000] 608). The EMEA expert committee had originally recommended prolonging authorization of these pharmaceuticals under specific conditions, but modified its appraisal later. The producers took the matter to the European Court of First Instance, which rejected the joint positions of the Commission and the expert committee (joined cases T-74/00, T-76/00, $\mathrm{T}-83 / 00$ to T-85/00, T-132/00, T-137/00 and T-141/00, 26.11.2002), because they relied exclusively on a modified appraisal of the safety and efficacy of the pharmaceuticals in question, and not on new scientific insights. Remarkably, the court examined the merits of the scientific opinion elaborated by the expert committee in great detail and delved into the substance of the authorization decision. Upon appeal by the Commission, the judgment was confirmed by the European Court of Justice (case C-39/03 P, 24.6.2003).

Access to judicial oversight is somewhat biased toward challenging negative authorization decisions. Generally, a private plaintiff can only bring a claim successfully to the European courts if he is directly and individually concerned by a Community action (Art. 230, formerly 173, of the EC Treaty). An applicant can easily demonstrate such concern because the relevant decision is directly addressed at him. He will be entitled to market a medicinal product if the criteria of safety, efficacy and quality are met (Collatz 1996: 134). In contrast, direct concern is difficult to prove for consumers or physicians, i.e. the immediate or indirect users of authorized pharmaceuticals, because they are usually not individually affected by an authorization decision. In a recent case, the European Court of First Instance denied the legal standing of an employee, who had been responsible for testing a pharmaceutical, because she was not individually and directly affected by the positive authorization decision (case T-326/99, 18.12.2003). Consequently, it is much easier for producers to take legal action against a badly reasoned negative authorization decision than for consumers to challenge an unconvincing positive decision. However, a member state might step in if it considers a positive decision to be scientifically unwarranted, because member states always enjoy legal standing.

The existence of substantive decision-making criteria and their supervision by the European courts are intended to guide the EMEA expert committee and limit its discretion. Legally binding substantive decision criteria provide a yardstick against which its opinions can be appraised and, if appropriate, challenged through judicial review instigated by states and non-state actors with 
legal standing. Moreover, an EMEA opinion not conforming to the binding substantive standards could also be challenged by the Commission and/or the Standing Committee in the later stages of the authorization procedure (see section 3.1). Hence, this arrangement is to provide an additional incentive for the EMEA expert committee to stick to its mandate - fully in line with the general concern of the principal-agent literature, that regulatory agencies must be hindered from shirking.

However, substantive decision criteria and their judicial supervision also limit the room for manoeuvre of the non-scientific actors involved in the European authorization of pharmaceuticals, namely the Commission and the Standing Committee representing the member states. Their action can also be appraised against the legally binding yardstick. Since applicants may take legal action, it is hardly conceivable that these actors deviate from a scientifically sound opinion of the expert committee without eventually being called back by the European courts. Accordingly, their action under the authorization procedure is effectively restricted to tacit oversight of whether the criteria are sincerely applied by the agency. Moreover, when elaborating the substantive criteria in their capacity as the European legislator, Commission, Council and the European Parliament are jointly forced to mould general rules applicable to an unknown number of future cases. Thereby, the principals are hindered from accounting for parochial interests in specific cases, because they are bound to devise a single set of substantive rules applicable to all future cases alike. Accordingly, capture by parochial interests becomes less likely (Gehring 2004: 689-90).

As a result, the authorization process is not integrated by the bargaining power of non-scientific actors any more, but by scientific reasoning within the limits of mandatory European law (see also Joerges and Neyer 1997). Legally enforceable substantive decision criteria increase the power of the scientific expert committee vis-à-vis the non-scientific actors, as long as it sticks to its mandate. They can be exploited best by the actors who are specialized in scientific expertise, whereas they deprive the non-scientific actors of their bargaining power. Thus, the effects of the second layer of oversight contribute to explaining the remarkable inactivity of the Commission and the Standing Committee under the authorization procedure observed in the preceding section.

\subsection{The third layer: internal oversight through EMEA standards}

A third layer of oversight arrangements is provided by internal EMEA standards which limit the discretion of the expert committee and reduce the uncertainty of applicants about the expected content of future authorization decisions. In spite of its detailed provisions, the legally binding substantive criteria for the assessment of the safety, efficacy and quality of pharmaceuticals do not fully abolish the discretion of the expert committee. This is especially due to the fact that authorization decisions always involve a trade-off between safety and efficacy. The more effective a product is, the more undesired side-effects it 
will generally cause (Heilmann 2002), and there will frequently be a range of possible ways of weighing effects against side-effects.

The authorization process is guided by a great number of internal standards of different types. They are far more detailed than the legally binding Community Code for Medicinal Products for Human Use. These standards constitute the principal instrument of the EMEA to inform possible applicants of the precise criteria upon which its scientific opinions are based (interviews at EMEA headquarters and at the German pharmaceutical authority [Bundesamt für Arzneimittel und Medizinprodukte]). They are elaborated by various working groups of the expert committee or emerge from the international conference on harmonization (ICH) founded by the United States, Japan and the EU to harmonize their national (or supranational) authorization of medicinal products (Vogel 1998). As of 1 June 2003, 146 Guidelines were in force, while twenty-four were in a draft stage, and twenty-three in the preceding conceptual stage. These documents reflect the position of the expert committee concerning areas of reliable scientific knowledge and experience. Moreover, twenty-four 'Points to Consider' documents had been adopted, while five were in the draft stage and nine more in the conceptual stage. In contrast to Guidelines, they address areas of pharmaceutical research and regulation in which considerable scientific uncertainty prevails. In addition, numerous Position Papers, Statements and other documents of inferior status were adopted or were in draft stages (see Krapohl 2005: 133-46).

Despite their informal status, these rules create a significant binding force on the expert committee because they cannot be ignored or changed at will. They are not legally binding and cannot be directly enforced by judicial review, because the task of rule-making is not formally assigned to the agency. However, they might well be used in legal proceedings as an indication of the state of the art of pharmaceutical research and experience. Authorization decisions that deviate from these rules will thus require particularly convincing justification. This is all the more true because Guidelines as the most reliable guidance documents are not only published by the EMEA, but also by the Commission (see Medicinal Products for Human Use: Guidelines, in EudraLex: The Rules Governing Medicinal Products in the European Union, Vol. 3). Like Points to Consider documents, they are developed in a formal administrative procedure, which includes publication of drafts and the consultation of stakeholders, such as pharmaceutical companies, consumer groups and the authorization bodies of the member states (see Standing Operating Procedure for Developing CPMP Guidelines and Points to Consider Documents; CPMP/2024/98).

Instead of exploiting its informally powerful status under the authorization procedure, the EMEA expert committee limits its margins of discrete choice through the elaboration and publication of numerous guidance documents. In its own interest of developing, and subsequently preserving, the reputation of producing scientifically convincing opinions, the agency chooses to voluntarily bind itself at the mast of institutional rules in order to enhance the 
credibility of its decisions. By committing itself to decisions that follow its own rules, the committee reduces the number of options that could be chosen and voluntarily cuts the room for manoeuvre for internal bargaining. Thus, it creates a strong incentive for deliberation about the appropriate application of legally binding and non-binding criteria (on the difference between bargaining and reason-based deliberation, see Elster 1998; Risse 2000). The output of a rule-based decision-making system will be more coherent and less arbitrary than decisions based upon ad hoc considerations.

\section{CONCLUSION: SUPRANATIONAL REGULATION THROUGH A COMPLEX REGULATORY SYSTEM WITH A SEMI-INDEPENDENT AGENCY}

The centralized authorization procedure for pharmaceuticals reflects a new approach to governance in the single market. It is characterized by the involvement of a strong regulatory agency as well as by the participation of a number of other actors, including the Commission, the member states and the European courts. In contrast to the comitology system existing in other fields of European governance, it differs significantly through its high degree of legalization and adjudication forcing all actors involved to accept guidance by legally binding substantive decision criteria.

The EMEA can act like an independent regulatory agency, although it is not formally independent. Its dominant position within the authorization process does not originate from its formal status, because authorization decisions are still formally adopted jointly by the Commission and the Standing Committee. Instead, it is rooted in the restrictions imposed on the non-scientific actors by the authorization system. These actors cannot exploit their formally strong position at the end of the authorization procedure because they must observe a voluminous collection of substantive decision criteria, which may be legally enforced by interested actors. This explains the observed inactivity of the Commission and the Standing Committee. Hence, restrictions preventing other actors from intervening in the day-to-day business of the agency operate as a functional equivalent to the agency's formal independence. We might conclude that measured degrees of independence of regulatory agencies to be found in the principal-agent literature (Gilardi 2002) do not necessarily correlate with the ability of these agencies to act independently.

In spite of actual non-interference of non-scientific actors in the day-to-day operation of the EMEA, the agency does not operate in the absence of effective oversight mechanisms. On the one hand, the authorization procedure includes a powerful fire alarm mechanism. If stakeholders or an outvoted member of the expert committee alert the Commission and/or the member states, EMEA opinions can easily be prevented from becoming legally binding authorization decisions. Hence, the Commission and the Standing Committee representing the member states fulfil an important oversight function, even if not becoming active, because they create an incentive for the EMEA to produce scientifically 
convincing opinions. On the other hand, the EMEA is, like all other actors involved, legally bound to observe the voluminous set of substantive decision criteria, which may be enforced by states and non-state actors with legal standing. The possibility for applicants to take legal action and the preparedness of the European courts to examine the merits of disputed opinions provide another strong incentive for the EMEA to produce sound opinions. The expert committee has responded to these incentives. The endeavour of the EMEA to elaborate numerous additional guidance documents contributes to avoiding arbitrary or unconvincing decisions which might undermine its reputation as a sound regulator and lead to the intervention of non-scientific actors. Thus, the expert committee limits its own discretion and successfully sidesteps the internal credible commitment problem which might arise from the fact that its members implicitly represent their domestic authorization agencies.

Instead of merely reallocating the decision-making power among the actors involved, the centralized authorization procedure establishes a regulatory system which submits all relevant actors alike to severe constraints and limits their room for discrete choice. It operates under the implicit assumption that the authorization of pharmaceuticals is, in essence, about the search for the most convincing decisions, not about discrete choice which characterizes redistributive decisions (Majone 1996: 28-47). The system limits the discretion of the agency which is induced to concentrate on its area of primary competence, namely scientific and regulatory expertise. It has to ignore all other aspects that might possibly affect the appraisal of an application, because its decisions may be appraised against substantive criteria. However, the rules also limit the discretion of all other relevant actors and thus shield the agency from outside pressure. The formally powerful oversight actors, i.e. Commission and member states, are deprived of their ability to mobilize non-scientific sources to influence authorization decisions, such as bargaining power and votes. And industry, although in close contact with the agency during pre-application and application stages, will hardly be able to influence the decision process except through information and convincing arguments based upon the substantive criteria. Thus, the system is designed to protect the decision-making process against particularistic interests, although it does note exclude actors with particularistic interests from participating in this process in specific functions.

The particular balance between autonomy and control reflected within the European centralized authorization procedure for pharmaceuticals is not fully grasped by any of the current theoretical approaches to delegation and agency decision-making. It reflects neither of the 'two logics of delegation' discussed by Majone (2001a). Neither the agent, nor the principals, i.e. the Council in collaboration with the Commission and the European Parliament acting as the joint European legislator, dispose of far-reaching discretion within the procedure. The institutional arrangement is also not easily accommodated with the alleged divide between industrialists on the one side and domestic licensing authorities as well as consumerists on the other side (Lewis and 
Abraham 2001; Permanand and Mossialos 2005). While it has been created as a market-making project and producers play an important role as applicants and as possible litigants, it is difficult to see how industry could dominate the authorization process. The licensing authorities, i.e. the domestic guardians of public health, are heavily involved in the elaboration of scientific opinions, but they are forced to adhere to legally binding standards and to agree on the common appraisal of every single product so that national idiosyncrasies are effectively filtered out. Rather than assigning unbound discretion to any of these actors, the system mobilizes the resources of all actors involved, whether private or public, member state or European, and drags them into common problemsolving in light of generalized substantive decision criteria.

Biographical notes: Thomas Gehring is Professor of International Politics in the Department of Social and Economic Sciences at Otto Friedrich University, Bamberg, Germany. Sebastian Krapohl is PhD candidate in the Department of Social and Economic Sciences at Otto Friedrich University, Bamberg, Germany.

Addresses for correspondence: Thomas Gehring, Department of Social and Economic Sciences, Otto Friedrich University, Bamberg, Feldkirchenstr. 21, 96045 Bamberg, Germany. email: thomas.gehring@sowi.uni-bamberg. de/Sebastian Krapohl, Department of Social and Economic Sciences, Otto Friedrich University, Bamberg, Feldkirchenstr. 21, 96045 Bamberg, Germany. email: sebastian.krapohl@sowi.uni-bamberg.de

\section{REFERENCES}

Abraham, J. and Lewis, G. (2000) Regulating Medicines in Europe: Competition, Expertise and Public Health, London: Routledge.

Abraham, J. and Lewis, G. (2002) 'Citizenship, medical expertise and the capitalist regulatory state in Europe', Sociology 36(1): 67-88.

Alter, K. J. (1998) 'Who are the "masters of the Treaty"? European governments and the European Court of Justice', International Organization 52(1): 121-47.

Cameron McKenna and Anderson Consulting (2001) Evaluation of the Operation of Community Procedures for the Authorisation of Medicinal Products, http:// pharmacos. eudra.org/F2/review/index.htm.

Collatz, B. (1996) Die neuen europäischen Zulassungsverfahren für Arzneimittel: Insbesondere Verfahren und Rechtsschutz des Antragstellers und Zulassungsinhabers bei Zulassungsentscheidungen, Aulendorf: Editio Cantor.

Cukierman, A. (1994) 'Commitment through delegation. Political influence and central bank independence', in J.O. de Beauford Wijnholds, S.C.W. Eijffinger and L.H. Hoogduin (eds), A Framework for Monetary Stability, Dordrecht: Kluwer, pp. 55-74.

Dehousse, R. (1997) 'Regulation by networks in the European Community: the role of European agencies', Journal of European Public Policy 4(2): 246-61.

Eberlein, B. and Grande, E. (2005) 'Beyond delegation: transnational regulatory regimes and the EU regulatory state', Journal of European Public Policy 12(1): $89-112$. 
Elster, J. (1998) 'Deliberation and constitution making', in J. Elster (ed.), Deliberative Democracy, Cambridge: Cambridge University Press, pp. 97-122.

Feick, J. (2000) 'Marktzugangsregulierung: Nationale Regulierung, europäische Integration und internationale Harmonisierung in der Arzneimittelzulassung', in R. Czada and S. Lütz (eds), Die politische Konstitution von Märkten, Wiesbaden: Westdeutscher Verlag, pp. 228-49.

Feick, J. (2005) Learning and Interest Accommodation in Policy and Institutional Change: EC Risk Regulation in the Pharmaceuticals Sector, Discussion Paper No. 25, London: London School of Economics, Centre of Analysis of Risk and Regulation.

Franchino, F. (2002) 'Efficiency or credibility? Testing the two logics of delegation to the European Commission', Journal of European Public Policy 9(5): 677-94.

Gardner, J.S. (1996) 'The European Agency for the Evaluation of Medicines and European regulation of pharmaceuticals', European Law Journal 2(1): 48-82.

Gehring, T. (2004) 'The consequences of delegation to independent agencies: separation of powers, discursive governance and the regulation of telecommunications in Germany', European Journal of Political Research 43(4): 677-98.

Gilardi, F. (2002) 'Policy credibility and delegation to independent regulatory agencies: a comparative empirical analysis', Journal of European Public Policy 9(6): 873-93.

Heilmann, K. (2002) 'Risiko und Sicherheit', Deutsche Apotheker Zeitung 142(11): 85-93.

Huber, J.D. (2000) 'Delegation to civil servants in parliamentary democracies', European Journal of Political Research 37(3): 397-413.

Huber, J.D., Shipan, C.R. and Pfuhler, M. (2001) 'Legislatures and statutory control of bureaucracy', American Journal of Political Science 45(2): 330-45.

Joerges, C. and Neyer, J. (1997) 'Transforming strategic interaction into deliberative problem-solving: European comitology in the foodstuffs sector', Journal of European Public Policy 4(4): 609-25.

Keech, W.R. (1995) Economic Policy: The Costs of Democracy, Cambridge: Cambridge University Press.

Kelemen, D.R. (2002) 'The politics of "Eurocratic" structure and the new European agencies', West European Politics 25(4): 93-118.

Kiewiet, R. and McCubbins, M.D. (1991) The Logic of Delegation: Congressional Parties and the Appropriations Process, Chicago, IL: University of Chicago Press.

Krapohl, S. (2003) 'Risk regulation in the EU between interests and expertise: the case of BSE', Journal of European Public Policy 10(2): 189-207.

Krapohl, S. (2004) 'Credible commitment in non-independent regulatory agencies: a comparative analysis of the European agencies for foodstuffs and pharmaceuticals', European Law Journal 10(5): 518-38.

Krapohl, S. (2005) 'Die europäische Arzneimittelzulassung', in T. Gehring, S. Krapohl, M. Kerler and S. Stefanova (eds), Rationalität durch Verfahren in der Europäischen Union: Europäische Arzneimittelzulassung und Normung technischer Güter, BadenBaden: Nomos, pp. 81-196.

Lewis, G. and Abraham, J. (2001) 'The creation of neo-liberal corporate bias in transnational medicines control: the industrial shaping and interest dynamics of the European regulatory state', European Journal of Political Research 39(1): 53-80.

Majone, G. (1996) Regulating Europe, London: Routledge.

Majone, G. (1997) 'The new European agencies: regulation by information', Journal of European Public Policy 4(2): 262-75.

Majone, G. (2001a) 'Two logics of delegation: agency and fiduciary relations in EU governance', European Union Politics 2(1): 103-21.

Majone, G. (2001b) 'Nonmajoritarian institutions and the limits of democratic governance: a political transaction-cost approach', Journal of Institutional and Theoretical Politics 157: 57-78. 
Majone, G. and Everson, M. (2001) 'Institutional reform: independent agencies, oversight, coordination and procedural control', in O. de Schutter, M. Lebessis and J. Paterson (eds), Governance in the European Union, Luxembourg: European Union, pp. 129-68.

McCubbins, M.D. and Schwartz, T. (1987) 'Congressional oversight overlooked: police patrol versus fire alarms', American Journal of Political Science 28(1): 165-79.

McCubbins, M.D., Noll, R.G. and Weingast, B.R. (1987) 'Administrative procedures as instruments of political control', Journal of Law, Economics, and Organization 3(2): 243-77.

Permanand, G. and Mossialos, E. (2005) 'Constitutional asymmetry and pharmaceutical policy-making in the European Union', Journal of European Public Policy 12(4): 687-709.

Pollack, M.A. (2003) The Engines of European Integration: Delegation, Agency, and Agenda-Setting in the EU, Oxford: Oxford University Press.

Risse, T. (2000) "“Let's Argue!" Communicative action in world politics', International Organization 54(1): 1-39.

Shapiro, M. (1988) Who Guards the Guardians? Judicial Control of Administration, Athens, GA: University of Georgia Press.

Shapiro, M. (1992) 'The giving-reasons requirement', University of Chicago Legal Forum, pp. $180-220$.

Shepsle, K.A. (1991) 'Discretion, institutions, and the problem of government commitment', in P. Bourdieu and J.S. Coleman (eds), Social Theory for a Changing Society, Boulder, CO: Westview Press, pp. 245-63.

Tallberg, J. (2002) 'Delegation to supranational institutions: why, how and with what consequences', West European Politics 25(1): 23-46.

Thatcher, M. (2002) 'Regulation after delegation: independent regulatory agencies in Europe', Journal of European Public Policy 9(6): 954-72.

Tsebelis, G. (1994) 'The power of the European Parliament as a conditional agendasetter', American Political Science Review 88(1): 128-42.

Vogel, D. (1998) 'The globalization of pharmaceutical regulation', Governance: An International Journal of Policy and Administration 11(1): 1-22.

Vos, E. (1999) Institutional Frameworks of Community Health and Safety Legislation: Committees, Agencies and Private Bodies, Oxford: Hart.

Final version accepted for publication 12/06/06 